\title{
ARTICLES \\ Conceptualization of Ecological Management: Practice, Frameworks and Philosophy
}

\author{
Milutin Stojanovic ${ }^{1}$ (1)
}

Accepted: 15 June 2019 / Published online: 21 June 2019

(c) The Author(s) 2019

\begin{abstract}
This paper investigates practice, frameworks and philosophy in the field of ecological management, a novel integrative approach to closing the gap between ecological and economic theoretical models and ecological and economic behavior. First, I will present the current status in this emerging field and discuss management in relation to various sub-disciplines, including agroecology, circular economy, industrial ecology, and urban sustainability. This provides a basis to analyze the theoretical frameworks found in profitable, ecologically-based businesses and identify key general features that characterize this approach, notably the relationships between: an enterprise's diversity and its economic resiliency; zero waste policies and societal and environmental impacts; and affordances of the local environment and business' long-term economic viability. Finally, the philosophical issues looming behind are discussed, notably problems regarding interdisciplinarity and the relation of ethical frameworks with management. Through use of the model-centered philosophy of science to disentangle some of these conceptual problems, I argue that ecological management has a unique place in sustainable development as an independent exploratory tool for constructing and testing economic and ethical models in the Anthropocene.
\end{abstract}

Keywords Ecological management · Ecological economics · Exploratory ethics · Ethics as design · Model-centered philosophy of science · Practical philosophy · Sustainability science

It would be very sad if the only students who studied economics were those who didn't realize the fundamental limits of the discipline. Daly and Farley, Ecological Economics

Milutin Stojanovic

stojanovic.m.milutin@gmail.com

1 Practical Philosophy and Helsinki Institute of Sustainability Science (HELSUS), University of Helsinki, Helsinki, Finland 


\section{Introduction}

Ecology has traditionally focused on isolated, pristine patches of nature; on a planet with seven billion humans and an encroaching technosphere, an approach destined for economic, political—and ecological-irrelevance (McNeill 2000). A direct way to tackle the misfires of traditional ecology would be to devise ecological actions that are at the same time economical. To investigate this direct approach to making ecology economical (and, eventually, economy ecological) various theoretical frameworks and strategies have been proposed in recent years, many of which revolve around principles of ecological economics (Daly and Farley 2010) or circular economy (Geissdoerfer et al. 2017). They include: circular economy, cradle-to-cradle laws of ecology, looped and performance economy, regenerative design, industrial ecology, biomimicry, blue economy, and others. The relation between ecologically embedded management and these and other theoretical assumptions remains unclear and, most importantly, it remains unclear whether ecological management is just a family of approaches practicing some of these vaguely related theoretical assumptions or if there is any genuine methodological unity within the field.

Most frameworks of ecological economics envision tackling the human predicament in the Anthropocene as requiring, first and foremost, a revolution in the methodology of economics and in economic representation, which will promote rather than inhibit the creation of new socio-economic structures and systems, that will ultimately result in more efficient and ecological modes of life and production (Costanza et al. 2014). This top-down approach assumes that actions at the individual (business or household) level will never be enough, on their own, to achieve a sustainable economy. However, emerging cases of ecological management point to a different dynamic, that significant and lasting societal and economic changes may come from the basis of a socio-economic system-from integration of different scientific disciplines and approaches at the level of individuals and business enterprises. An important related assumption of the topdown approach is to conceptualize ecological economics (EE) as a reductio ad absurdum of classical economics (Daly and Farley 2010), mainly through the perceived undermining of the resource base that makes economics possible. Without challenging this reduction, this paper follows a case-study approach and argues that it will provide a more detailed model of ecological management and a more practical account of how management can be embedded in ecosystem processes; compared to models derived from the theory of ecological economics. On this basis, the paper challenges the usual understanding of ecological management (eco. man.) as just an application of ecological economics and argue instead for its independent place in the construction and testing of economic and ecological theoretical models-which would place it at the center of theory-experiment dynamics in Sustainability sciences.

This reversal of the usual EE reasoning prompts us to investigate grassroot managerial practices focused on the central themes of circular economy, especially those developed in the absence, or in spite, of governmental policies. The 
following section will focus on current practices and provide a closer look at the emerging field of ecological management. These instances of economically successful and environmentally embedded managerial practices suggest a conceptualization of ecological management, which "Emergent Principles of Ecological Management" section offers-discussing the operating principles, applied models and theoretical frameworks. "The Philosophy Behind Ecological Management" section discusses background philosophy, specifically relationship of eco. man. with ethics. It promotes understanding of eco. man. as exploratory ethics and, following Caroline Whitbeck's 'ethics as design' approach (Whitbeck 2011), formulates an approach to management that includes not just ethical judgements but also synthetic devising and refining of managers' actions in complex normative contexts. "The Philosophy Behind Ecological Management" section also discusses the elementary methodology of the sustainability sciences, which grounds the interdisciplinary modeling matrix that ecological management typically seems to require. The final section concludes by summarizing the main argument and discusses a background problem regarding the role of education.

\section{Studies and Practice}

Over the last 30 years or so, and especially in the last decade, management activities and scientific studies integrating management and environmental preservation have multiplied and propagated. The cognitive gaps between conventional management and ecology are in most cases overcome by applying the theoretical framework of ecological economics in an attempt to create a genuine interdisciplinary approach (see Daly and Farley 2010). Much of the emerging practice and related discussions revolves around the idea that management models based on ecological economics can be as profitable as conventional managerial models, while allowing consumers to continue enjoying equal or better products and services, without extra costs for other economic or extra-economic agents (e.g. Geissdoerfer et al. 2017). The nexus between extra-economic impact and profitability was adopted as the core for this class of models mainly because previous attempts to preserve ecosystems or communities have come to be viewed as fundamentally flawed due to the lack of economic incentives for such preservative actions (McNeill 2000). It has been imperative to identify new models of management which simultaneously tackle environmental and social issues on the one hand and financial profitability on the other, and to demonstrate these models in practice. The outcome has been initially, and starkly, reflected in agricultural management, in the context of agroecology, and more recently in urban and industrial managerial contexts related to circular economy.

Agroecological methodology is centered around biologically-based principles such as biodiversity, recycling of nutrients, synergy and interaction among crops, animals and soil, etc. Agroecology provides the framework for a form of management (and technological innovation) focused on design instead of engineering, and organization instead of control of nature (Stojanovic 2017). It attempts to structurally replicate local ecosystems, mainly through incorporating natural species into 
the management of agroecological systems, by using them to manage specific functions in the agro-system and thereby obtain profit from the byproducts of the ecosystem functions of integrated species (Hendrickson et al. 2008). Environmentally and socially sensitive problems related to agriculture (such as social equity and the ecological sustainability of a system) are tackled by managing diverse farms, integrating production goals, and grounding them in local ecological and socioeconomic setting (Altieri et al. 2017). Both resource-conserving management and long-term sustainability focus are adjusted to different local farming conditions and local farming knowledge such as the availability of local practices, knowledge, and the bioregion's specific potentials. A focus on diverse on-farm resources and inputs, and incorporation of biological scientific principles in farming systems, it is argued, often provides the only practical and cost-effective way in economically underdeveloped areas to restore agricultural lands degraded by conventional agronomic practices (Shi and Gill 2005). Human resource development (e.g. promoting education and natural-system observation) is sometimes presented as a way to open up options for developing marginal areas overlooked by conventional agriculture, thereby facilitating the claim that ecological management provides a unique opportunity to increase social equity by providing revenues for smallholders (Magdoff 2007). However, ecological agriculture, specifically in the developing world, is often at an economic disadvantage due to subsidies for resources, energy and land commonly provided for industrial agriculture, regardless of the destruction of the natural capital of the countries in question (McNeish 2018).

A well-known case that demonstrates this point is the agroecological management of hillside agricultural areas of Latin America in the face of economic crisis in the 1980s (see Altieri et al. 1998). In the last two decades of the twentieth century, Honduras, Bolivia, Peru, Chile, and Cuba faced a crisis in agricultural production due to the combination of difficult and degraded soils, and constraints in agricultural inputs and capital. On many farms, instead of chemically fertilized and mechanically prepared fields, a variety of managerial technologies and practices were introduced in response to the crisis and distributed via NGOs and farmer-advisory institutions, promoting a managerial model of diverse farms in which each farm component biologically reinforces the other components. Diversifying management included integration of fruit trees and animals, extensive usage of cover crops for weed protection and land reclamation, organic fertilization, companion planting, spatial and temporal rotational sequences of forage and row crops, and other regionspecific agro-techniques. Crucially, specific agro-components combinations were chosen based primarily on local agro-climatic conditions and peasant consumption patterns, and only secondarily on market opportunities. For example, cropping systems designed specifically for the hillside regions were developed in Honduras using local resources (rocks, physical labor) and inputs produced on-farm (organic waste, manure) to both reduce erosion (such as drainage and contour diches, grass barriers, and rock walls) and restore the fertility of degraded soils (intercropping with legumes, chicken manure, etc.). The techniques achieved unimaginable results from the conventional agricultural perspective, moderating temperature, extending the growth season and raising productivity, while restoring previously degraded soils and providing employment and income in economically depressed areas. In Bolivia, 
experimentation has focused on green manure and cover cropping, replacing chemical fertilizers and mechanic land-preparation while providing livestock feed. Although yields were generally lower than with chemical fertilizers and machinery, the costs were also lower, generating a greater net economic benefit in agroecological systems (ibid.).

In recent years, eco. man. is expandingly practiced in urban and industrial contexts related to circular economy. In the residential context, it takes the form of zero net energy architecture, although with divided focus on either energy conservation or (the more usual) renewable energy harvesting (Eiffert 2003). In some cases, it is focused on closing urban waste streams through waste separation and usage for heating or electricity production-i.e. by processing bio-waste into bio-fuel (in organic digesters), running power plants on combustible waste, and/or compost production for agricultural fertilizers (Werner 2017). Both approaches contribute to closing urban heating and electricity loops and bringing cities closer to the zero net energy ideal.

In other cases, circular economy in an urban setting is practiced through incorporation of urban agricultural production, food preparation and food education into the existing industrial building stock and local social infrastructure (van Veenhuizen 2006). A case in point is an industrial symbiosis of sixteen food and education businesses from Chicago, located in a repurposed decommissioned meat packing facility known as The Plant (Chance et al. 2018). A brewery, greenhouse, urban outdoor and indoor farming, mushroom farming, commercial kitchen, bakery, education center and other food-related businesses are all intertwined in their resource streams (wastes or outputs of one being inputs for another) ${ }^{1}$ and the entire collaborative community creates resource-loops with the city of Chicago by utilizing its food waste and in return providing food, energy and social impact (Plant 2017). Specific managerial solutions for closing resource and energy loops in The Plant are often accompanied by education of the local public regarding food and waste awareness (through demonstration farms, educational programming, public tours and workshops, and provision of healthy food) and with open-source spreading of managerial practices-spawning similar projects elsewhere throughout the city and beyond (Chance et al. 2018). The fields of urban agriculture and urban waste management are still in their infancy and face many challenges, although they are rapidly evolving, and the majority of projects are still focused, in one way or in the other, on exploring ecological production opportunities in a given socio-environmental setting (Pretty 2009).

In a strictly industrial setting, the principles of circular or biobased economy guide managers in minimizing both resource input and waste, emission, and energy leakage in industrial processes, ultimately creating a circular flow of materials and cascading energy flows (Geissdoerfer et al. 2017). Despite this theoretical foundation, empirical research and application of environmental measures in

\footnotetext{
1 e.g. Wastes from food preparation, aquaponics and mushroom growing are used for heating purposes (through an anaerobic digester) or for composting, which is further used for agricultural food and feed production.
} 
energy management remain widely neglected in key industrial sectors such as the manufacturing industry (Schulze et al. 2018). Sustainable practice remains narrow in scope and the findings reveal that the material footprint of global industry has increased massively in the last 50 years and accelerated since 2000 - at the same time, driven by industrialization and urbanization in the global South, producing negative impacts on a suite of environmental and social issues, including natural resource depletion, climate change, loss of biodiversity, and uneven economic development (Schand et al. 2018). Although this indicates that such systems are a long way from being ecologically sustainable, emerging methodology is developing into a valuable scientific asset. As rising concerns about global warming put a previously unimportant waste flow, carbon dioxide, on top of the political and scientific agenda, the material flow analysis (based on the law of conservation of matter and energy) has become an important tool in studying the circular economy empirically across sectors and in devising specific managerial strategies by quantification of resource flows and social impact, as part of the broader sustainability impacts of a facility (cf. Chance et al. 2018).

Models and experiments have recently increased in industrial management, although commercial models of industrial ecology-industrial symbiosis networks such as Kalundborg Eco-Industrial Park in Denmark-remain rare in both theory and practice (Chertow 2000). Some emerging cases demonstrate that, instead of in industrial symbiosis (i.e. eco-industrial parks), principles of circular economy can also be applied at a small scale, within a single small/medium enterprise. The Pocheco envelope plant in France is a case in point, where local energy cascades and material mini loops are created inside a single factory (Pocheco 2018). Pocheco is implementing their version of the principles of circular economy: active minimization of inputs and waste-recycling inside the factory; incorporation of living systems for food, fuel, and specific waste management tasks; and reduction of harsh working conditions and rise of social equity. It consists of a single wood-source envelope factory which was gradually reformed (and is still undergoing changes) by the replacement of unsustainable practices and production processes. For example, a reforestation planting policy of 4 sprouts for 1 tree was enacted, coils for envelopes were introduced, reducing the consumption of cardboard boxes by around 200 thousand yearly, and biodegradable detergents are used for cleaning machines (eliminating toxic waste water). As a follow-up a bamboo grove was planted to purify the washing waste-water and the bamboo is then used to fuel the central heating system (which together with the wood pellets from tree residues in envelope making and heat recovery from the machines produces $100 \%$ self-sufficiency in terms of heating). Investment in the factory roof enabled both electricity production from solar panels and collection of rainwater for internal use-creating water self-sufficiency for the factory (for washing the machines, diluting ink, and toilet use), and also an artificial meadow for bee-keeping and roof insulation in the form of earth and plants. On the social side, the factory management mounted a leverage buyout of the company's shares, effectively and openly rejecting financial capitalism, and systematically reinvesting the company's results in itself, instead of paying dividends. Social equity is promoted in different ways: for example, the pay ratio has risen to $1-4$, and fruit trees and vegetables are organically grown in all available areas on the 
site and are available for employees' consumption (Pocheco 2018). Although they have recently proliferated, small-scale ecological enterprises of this type remain scientifically under-investigated.

In summary, there are essential similarities in managerial practices across the mentioned sectors, mostly in their focus on efficiency and circularity of energy and material use, and on knowledge distribution. Yet in most cases where ecological management is practiced, it is practiced atypically, without the preserved conceptual and methodological unity of ecological economics (Mulrow et al. 2017). In the remaining sections, I will try to delineate a framework for this atypicality and the basic principles underlying it, as well as to provide it with some philosophical grounding,

\section{Emergent Principles of Ecological Management}

The key conceptual framework engulfing examples of ecological management is resilience - the capacity of an enterprise to absorb disturbance, both from economic shocks and natural causes. It is a framework for understanding how persistence and transformation coexist in living systems, including human societies (Scheffer 2009; Buheji 2018). It often includes not only an industrial symbiosis which creates a resilient economy in the form of propagating many interconnected businesses (Chertow 2000), but, importantly, diversity within an enterprise (through many interconnected projects). This not only strengthens general economic stability, but also the local social stability, which further increases the enterprise's resilience and capacity to sustain itself. In practice, instead of focusing on profit and growth, resilience primacy focuses eco. man. on both the sustainability of resource-flows and on qualitative social development (Schand et al. 2018). In the later, analogously to the motto 'there is no farming without farmers' (Gala 2005), the focus in emerging studies is not merely about efficiently using the employees, but instead on nurturing a workforce, tackling the problem of their quality of life, broadly understood (Chance et al. 2018). This can be done in a number of ways: for example, by organic, on-site food production for employees, no-waste protection of the local environment, ongoing education and similar policies. The underlying idea is that limited human management, as it is commonly practiced, produces a weak socio-economic base in the long term and results in, holistically looking, inefficient management. From the strictly economic perspective, the focus is not on the circular flow of money, but on the thermodynamically irreversible flows of matter and energy (Rees 2003). As many recent emergences of local currencies show (e.g. the Bristol pound), the material flow analysis is circumventing the financialization focus of classical economics by trying to close the loose loops of local economic activities-sometimes, as in the Pocheco case of heating the premises with bamboo grown on wastewater originating from rain catchment, closing a loop within the enterprise itself (Pocheco 2018). When closing a loop inside the enterprise is not possible, material flow analysis generally leads to a version of the economic strategy known as local import substitution (Shuman 2006), closing a loop locally (i.e. with economic subjects that share the same environmental and social pressures and responsibilities). 
The wider scientific background for this dual societal and material focus of management is the nested hierarchical relationship of the relevant spheres of interest, in which an economy is envisioned as part of society, which is a part of its environment (Griggs et al. 2013). This theoretical structure explains how creating disorder in the higher levels of the hierarchy exacerbates problems down the chain, and vice versa (Foley et al. 2011). Resulting framework renders growth inefficient after a certain point determined by the carrying capacity of the enterprise's support systems, illuminating that societal and environmental erosion undermines the long-term viability of growth policies accompanied by limited responsibility (Rees 2003). By rejecting expansionist (cornucopian) economic assumptions (exemplified in the belief that 'all the economic and societal problems will be solved when we are all rich'), the above examples of eco. man. suggest a possible evasion of the conflict between economic development and environmental protection by integrating development into global and local ecosystems functions.

However, since even the circular economy may lead to perpetual growth (Zwier et al. 2015), and thereby destroy the finite, higher levels of the nested hierarchy, this paper argues for a bio-inspired conception of economic systems. They, as almost any other living organism on Earth, must have a limit, the optimal scale (cf. Rees 2003). An emergent feature of the case studies is that optimal scale is something determined locally, relative to a particular ecological configuration and social situation, where both ecological dynamics and social values determine the proper path for management. Although the precise meaning of 'local' is elusive, affordances provided by a particular socio-environmental setting can enable managers to evade the main problem related to ecological crisis - the huge gap between our ethical judgements and ethical behavior (Blok 2015) - by pursuing economic development and environmental protection at the same time, using the same set of actions. By advancing the foregoing methodological framework, ecological management may provide a working model for sustainable development which directs economic growth in profitable societal and ecosystem functions, and limits enterprise's optimal scale relative to the economic capacity of the basic socio-environmental setting. With the development of the foregoing methodology, interesting possibilities may emerge for understanding social factors that specify the optimal scale, such as demographics and population preferences; these relations await further investigation (see Folke et al. 2011).

\section{The Philosophy Behind Ecological Management}

Due to the intertwining of the social, economic, and environmental spheres, ecological management is markedly characterized by a holistic approach, where assessment of its specific problems is possible only through a comprehensive analysis. Most importantly, it is an understanding of management in which not only the means but the ends of economic activity require philosophical reflection. Here, I adhere to the old (Adam Smith) idea that economics is essentially a moral philosophy (Weinstein 2007), and management a moral philosophy applied. If anagnorisis of sustainable development is the realization that the economy is, as any organism, analytically 
inseparable from its environment (Lovelock 2005; Latour 2017), then the nature of the human predicament on a finite planet poses the following managerial problem: what is the purpose of an economic enterprise? What are the possibilities to position enterprises and economies towards the accelerating planetary entropy and what is an appropriate managerial reaction to sudden awareness of the real situation, where traditional management has actually increased chaos globally? The problem of purpose is as shocking in its Anthropocene-scale as it is surprising at what aspect traditional management has failed in-abstractly speaking, at the autistic, GDP focus of (neo) classical economics (Daly and Farley 2010, pp. xxi), namely the abnormal subjectivity of financial focus and the related narrow range of success-assessment.

Understanding management as "a moral philosophy applied" obviously needs a clarification. First of all, it is important to explicate that every managerial action has an underlying set of ethical assumptions. As there are no stories about Nature or society without values imbedded in them (Marshal and Lozeva 2009), there are also no stories about economies without values imbedded in them. ${ }^{2}$ Secondly, acting on a set of ethical assumptions in new, unique circumstances or a novel managerial enterprise, makes a new, unique instance of the underlying ethical system (i.e. a new model) and provides feedback on the original ethical conception. This makes management a practical experiment in ethics. To use a simplified example, if we operate a business with a significant environmental footprint, say a traditional fossil fuel power station, we instantiate and spread an ethical system where air and water contamination is specifically weighted as acceptable relative to the other values at stake like production quotas, job creation, resource availability, financial profitability, etc. In contrast, the respective eco-friendly design, e.g. a bio-fuel power station (ceteris paribus), could manifest one of many ethical systems with a different specific relative value of environmental impact and other managerial ends; or a differently entangled hierarchy of values; or it could manifest a system with novel or restricted core values. In all these cases, how we govern these designs and businesses is an experiment in precisely what instances of an ethical system are feasible, what are the (often implicit) relations and primacies of underlying values, what are the real (and imagined) benefits of the related theoretical ethical systems, and, ultimately, an exploration of how a humane, enlightened ethics can be precisely formulated. Management proves to be a key, practical step in a spiral of formation of our ethical systems (from theory to experiment and back again). ${ }^{3}$

Besides testing and making models more concrete, a practical step is also required (and crucial) because ethical problems have an ingrained need for a response and many

\footnotetext{
2 As Stiegler (2015) has pointed out, although it seems like an elementary blunder to present ideas regarding the allocation of resources without discussion of the ethical theory of fair distribution, presentations of this kind are still not uncommon; as well as related presentations of data processing without discussion of data theory.

3 The methodology I investigate and defend in this paper is in part similar to the exploratory ethics approach of Weinberg et al. (2008), which entails that most ethical judgements can be realistically assessed only through empirical analysis of the relevant judgements. In our view, however, the focus is not on the judgements but on managerial acts/systems, that is on the instances of ecological design and management. Also, the focus is on management systems because they provide, along with the exactness of the empirical approach, concrete models of underlying ethics, which enrich the subsequent stages in the development of ethics, as illustrated above.
} 
moral decisions can be made only relative to the specific context in which we face them. This feature places ethical problems in analogical relation to a variety of design problems, from designing a space or devising a work schedule, to designing an experiment (Whitbeck 2011). The importance of this analogy is in appropriately valuing and accounting for synthetic ethical decision making as an integral part of moral practicea perspective usually neglected in most of ethics and applied ethics (Ibid.). Furthermore, specific to the fields discussed here, synthetic decision making in management and sustainability sciences typically happens in a complex moral landscape, containing 'wicked problems' (Blok 2016) and lacking unambiguous solutions and clearly right or wrong moral choices. Contrary to the perspective of a judge or that of a disengaged critic, managers are pressed to choose from options provided by the given socio-environmental setting, which are often not commensurable among each other, where possible responses are under-defined and the problem setting is ambiguous in nature, as well as to design solutions that have a complicate ethical status (that often includes facing a whole series of smaller problems and balancing the tradeoffs between alternative solutions and values that may not be simultaneously satisfiable). Therefore, when a set of ethical responses is materialized in the course of managerial design and governance of an enterprise, a new concrete and specific ethical system is created, giving new, nuanced meaning to the original abstract sets of right or wrong statements, delineating what is possible, realistic and worthwhile, and where even excellent solutions to an ethical problem may be improved upon in many cases. As Caroline Whitbeck has stated:

Many ethical problems that are represented as conflicts are better understood as problems with multiple demands and ethical constraints, constraints that may or may not turn out to be simultaneously satisfiable. [...] The multiply constrained nature of many problems in engineering design provides an excellent model of challenging ethical problems involving many types of moral considerations, all of which must be taken into account. $(2011,72-3)^{4}$

One background issue is of particular interest in modeling ethics in practice. Namely, if we perceive management as exploratory morality, are we not saturating secular life with moral values, seemingly contrary to the development of civil rights of the last few centuries, which has explicitly tended to promote personal freedoms against the dictum of contemporary ethical systems? Of course, what counts as saturation is a tricky question since the same moral freedoms (specifically in economic behavior) that have provided so much of humanity's current progress (see Gordon 2017) have also brought about the planetary ecological crisis (Crutzen and Schwägerl $2011)^{5}$ (and also social crisis in some cases, if we count for example the phenomenon

\footnotetext{
${ }^{4}$ I am deeply grateful to an anonymous reviewer for pointing out to me the similarities of Whitbeck's approach to that developed in this paper.

5 The short extraordinary period of growth 1870-1970 ("the golden century') makes this environmental destruction exceptionally hard to perceive (Gordon 2017). Apparently, it is a case of observation selection problem-due to our unique history (e.g. the planet was not destroyed by nuclear war during the cold war), we perceive the possibility of nuclear destruction during 20th c. as less probable than it actually was. By analogy, due to the extraordinary growth of the 1870-1970 golden century, we perceive the economic space for (future) growth as (potentially) greater than a more thorough analysis reveals.
} 
of nationalism and the world wars of the 20th century (cf. Berlin 2013/1979; Bataille 1991). ${ }^{6}$ Of course, it is beyond the scope of this paper to investigate how the Anthropocene affects the problem of basic human freedoms or what options for freedom are left-i.e. where is that elusive line between freedom and long-term safety. I put this issue forward, however, to clarify that the aim of the experiential approach to management is not to reinstall the primacy of ethics, but to change the perspective. Contrary to widespread normative approaches in philosophy of management and economics, which provide an ethical framework that acts as a vantage point to define "what ought to be', the approach defended here tries to delineate in practice which models of ethics are actually implemented, how informative/detailed they are, and how the remaining model-features are constructed. Accounting for 'how ethics is explored in management' through description of autonomous ethical-model-building procedures has as its aim to essentially turn the ethics-in-management debate from a theoretically dominated, upside-down approach to a perspective based on practice.

This being said, a consequence of experiential approach indeed is an increased role and awareness of ethics in human economic activities. Even if it purports a different (practice-oriented) kind of ethics, it incapacitates us to conceive management in the Anthropocene as not being value-laden. Although management has never been completely value-free, specific context of the Anthropocene calls for a scientifically informed extension of ethical theories and conditions them to a certain degree with developments in sustainability sciences. ${ }^{7}$ Although in a world with abundant natural resources it is perhaps possible to disassociate management from exploratory ethics and claim that economic activities lie in the sphere of private values (and to practice e.g. laissez-faire economics, free of social regulations), in the state the humanity finds itself in the Anthropocene, with strained resources and diminishing social values, the disassociation of management and ethics seems more like a symptom of ecological dysfunction in the evolution of society (Krall 2018). As Vallor succinctly states, "if you believe that the world is alright, you must be either obtuse or profoundly isolated by privileges" (Vallor 2017). In the existential crisis we all share, in which it is impossible to think about the cup of coffee you are drinking without thinking about the ecological footprint its path to your table made (Zwier and Blok 2017), eco. man. reveals itself as an ethically dense practice and, potentially, a new prime way to convey a moral message in the Anthropocene. If I may paraphrase Vallor again (2016) —an attempt (together with ecological tech-design) ${ }^{8}$ to "fix the

\footnotetext{
${ }^{6}$ The complexity of this issue is another inclination towards the nested hierarchy approach promoted here, since the problem involves not only environmental, but social, cultural, psychological and other dimensions as well. I shall return to this interdependence of dimensions and problems, and how can we account for them, in the following passages.

7 I am gratefully indebted to an anonymous reviewer for bringing to my attention this point regarding the historical interplay between values and freedom in ethics and economics-particularly for pointing out to the need to carefully distinguish ethical theories from more comprehensive world views.

8 eco. man. is tightly connected to the question of whether we can design technology so people can perform moral acts without being aware (e.g. waste separation via multiple recycling bins). This question of technology goes hand in hand with the question of whether we can design management so that businesses can perform moral acts without explicit intention. This part about 'automatic morality' does not pertain to exploratory management, but to those many instances of management which, as in most other activities, are not exploratory but repetitive.
} 
broken world', where old purposes were constructed for centuries without connecting economic reasoning and behavior with ethical considerations.

In the context of sustainability sciences, practicing ethics and learning ethical lessons from eco. man. acquires a scientific institutional framework. Pluralistic context posited by sustainability sciences (including even stakeholders and spreading democracy thereby) provides managers with the methodology to guide their choices and navigate ethical and business dilemmas in an increasingly complex and integrated multidisciplinary field (Klein et al. 2012). Although transmission of knowledge is paramount for scientific objectivity, the atypicality of each socioenvironmental setting makes learning ethical lessons from other multidisciplinary experiments difficult (Caniglia et al. 2017) (related to the problem of transferability of results in the sustainability sciences) and places more weight on transmitting the design principles and ethical tradeoffs, instead of direct learning of specific solutions. Within these and related limits, I argue for an interdisciplinary approach to management and for the insufficiency of analyzing only economically relevant data, without considering background social dynamics, cultural trends, ethical goals and environmental limitations. Specific knowledge from these fields is precisely what enables eco. man. to integrate itself into broader ecological dynamics with its economic benefits. Importantly, we must include other forms of human values than those related to economic efficiency, such as intergenerational heritage, emotionally durable designs, environmental protection and a plethora of other democratic concepts from the sustainability sciences. Incorporation of these perspectives into economic analysis can be a way out of Berlin's hell, where predictions of even the most significant social upheavals stay out of the reach of the social sciences (Berlin 2013/1979) due to their fracturing into theoretically isolated disciplines (Apostel et al. 1972) and myopic focus on established idealized and simplified theoretical models (Morgan and Grüne-Yanoff 2013). Exploratory ecological management is promulgated here as a way to incorporate various scientific models of nature and society, and reconnect, again and again, our theoretical constructs from sustainability sciences with the shifting social and environmental conditions.

\section{Conclusion}

Conceptualizing eco. man. as an applied moral philosophy results in management becoming essentially an educational as much as an economic activity. Education is engrained in eco. man. on many different levels, from acquisition of complex multidisciplinary knowledge from sustainability sciences to the problem of nurturing both employees and consumers - by promoting education, questioning and changing values, and thereby influencing the demand side of the economic problem. ${ }^{9}$ However, together with the communicational problem of identifying shared values, education lurks as potentially the biggest weakness of ecological management, since

\footnotetext{
9 Thereby tackling the problem of economic supply and demand from both sides thereby biting the bullet of the wicked bootstrap problem of sustainable development (cf. Blok 2016).
} 
its holistic approach, in sense of complexity of components and depth of analysis, requires far more knowledge-intensive management than that traditionally practiced-limiting the feasibility of its application. What counts as knowledge-intensive is directly related to the cognitive capacities and standards of the target social group. Although group knowledge level and learning capacity is something that differs on case to case basis, it seems there is a wider background for accommodating various levels of knowledge intensiveness in the nested hierarchy framework, making eco. man. heavily engaged in education, both directly by spreading ecological ideas necessary for its comprehension and practice, as well as indirectly by demonstrating concrete ecological production and organizational possibilities.

Regarding a common critique of ecological economics - that it does not give clear enough suggestions as how can we limit or end growth-analyzing its application in eco. man. reveals that thinking that the human crisis is a problem requiring specific measures (e.g. a technological solution) for what is actually a profound social and evolutionary problem of humans (Krall 2018) only retains the same systemic situation-and possibly creates new problems, generated by that solution. Changing our social perception of the world is a precondition for disengaging or avoiding a possibly eco-destructive evolutionary path. In other words, I argue that the planetary crisis is essentially tied into lagging education (cf. Sachsenmaier 2013; Gordon 2017) and that problems regarding education starkly reflect the ethically dense character of Anthropocene-related issues. A radical change of the place of education in the economy is necessary to divert the human evolutionary path and disengage the global economic system from eco-destructive practices, if the change is possible at all (cf. Krall 2018). Some strategies are already emerging from certain cultural milieus such as the League of European Research Universities, where scientists of all trades are called to urge a revolution in education on all levels (independent of political actors), with minimal starting goals to raise national scientific budgets at least to a level greater than the respective defense budget, and ultimately surpassing it significantly (LERU 2018). This is a long and slow intergenerational process, however, especially difficult in a world with a diminishing middle class, ${ }^{10}$ and whether it is appropriate in the face of impeding climate crisis should be a topic for further investigation.

Although many institutions, authors and local initiatives already argue for massive changes in the growing problem of public education, much greater momentum seems necessary for the monumental educational (and societal) changes the Anthropocene seems to require. Eco. man. could take a leading role in this developing social dynamics by exploring and demonstrating new pathways for working and

\footnotetext{
${ }^{10}$ This issue regarding the middle class has a peculiar ecological perspective. Since both the affluent and poor social classes have no reason to abstain from unlimited economic growth (McNeill 2000): the former because they do not experience scarce resources or direct ecological backlashes (e.g. shortages in agricultural produce) - a precondition for no-growth policies; and the latter being in too urgent a situation to consider long-term problems (OECD 2014). Furthermore, since education is not perceived as an existential (i.e. intrinsic) goal in either group in general, the problem of the diminishing middle class globally represents a grim dynamics for the capacity of humanity to tackle the Anthropocene's planetary crisis.
} 
living integrated into ecosystem processes, and at the same time be engaged in the exposure of the social concealments regarding underlying economic assumptions by testing them against various models from social, environmental, and sustainability sciences.

Acknowledgements Open access funding provided by University of Helsinki including Helsinki University Central Hospital.

Open Access This article is distributed under the terms of the Creative Commons Attribution 4.0 International License (http://creativecommons.org/licenses/by/4.0/), which permits unrestricted use, distribution, and reproduction in any medium, provided you give appropriate credit to the original author(s) and the source, provide a link to the Creative Commons license, and indicate if changes were made.

\section{References}

Altieri, M., et al. (1998). "The potential of agroecology to combat hunger in the developing world" in International food policy research institute. A 2020 Vision for Food, Agriculture and the Environment. http://www.ifpri.org/publication/potential-agroecology-combat-hunger-developing-world. Accessed 3 April 2018.

Altieri, M., et al. (2017). Technological approaches to sustainable agriculture at a crossroads: An agroecological perspective. Sustainabilty. https://doi.org/10.3390/su9030349.

Apostel, L., Berger, G., Briggs, A., \& Michaud, G. (Eds.). (1972). Interdisciplinarity: Problems of teaching and research in universities. Paris: Organization for Economic Cooperation and Development.

Bataille, G. (1991). The accursed share, Volume 1: Consumption. New York: Zone Books. ISBN 0-942299-11-6.

Berlin, I. (2013/1979) Nationalism: Past neglect and present power. In Against the current: Essays in the history of ideas. Princeton University Press, pp. 420-448.

Blok, V. (2015). The human glanze, the experience of environmental distress and the 'Affordance' of nature: Toward a phenomenology of the ecological crisis. Journal of Agricultural and Environmental Ethics. https://doi.org/10.1007/s10806-015-9565-8.

Blok, V. (2016). Biomimicry and the materiality of ecological technology and innovation: Toward a natural model of nature. Environmental Philosophy, 13(2), 195-214. https://doi.org/10.5840/envirophil 201692035.

Buheji, M. (2018). Understanding the power of resilience economy: An inter-disciplinary perspective to change the world attitude to socio-economic crisis. UK: AuthorHouse. ISBN 1546286667, 9781546286660.

Caniglia, G., et al. (2017). Experiments and evidence in sustainability science: A typology. Journal of Cleaner Production, 169, 39-47.

Chance, E., et al. (2018). The plant-An experiment in urban food sustainability. Environmental Progress and Sustainable Energy, 37, 82-90. https://doi.org/10.1002/ep.12712.

Chertow, M. (2000). Industrial symbiosis: Literature and taxonomy. Annual Review of Energy and the Environment, 25, 313-337.

Costanza, R., Cumberland, J. H., Daly, H., Goodland, R., Norgaard, R. B., \& Kubiszewski, I. (2014). An introduction to ecological economics (2nd ed.). Boca Raton: CRC Press.

Crutzen, P. J., \& Schwägerl, C. (2011). Living in the Anthropocene: Toward a new global ethos. Yale Environment 360. http://e360.yale.edu/feature/living_in_the_anthropocene_toward_a_new_globa 1_ethos/2363/. Accessed January 20, 2017.

Daly, H. E., \& Farley, J. (2010). Ecological economics: Principles and application (2nd ed.). Washington: Island Press.

Eiffert, P. (2003). Guidelines for the economic evaluation of building-integrated photovoltaic power systems. National Renewable Energy Laboratory: Technical report January 2003. https://www.nrel.gov/ docs/fy03osti/31977.pdf. Accessed 15 Sept 2018.

Foley, J. A., et al. (2011). Solutions for a cultivated planet. Nature, 478, 337-342.

Folke, C., et al. (2011). Reconnecting to the biosphere. Ambio, 40(7), 719-738. 
Gala, R. (2005). Agriculture without farmers _ The WTO and EU agricultural policies are sweeping farmers off the land in droves and threatening world food security. http://www.i-sis.org.uk/AWF. php. Accessed 14 May 2018.

Geissdoerfer, M., Savaget, P., Bocken, N. M. P., \& Hultink, E. (2017). The circular economy-A new sustainability paradigm? Journal of Cleaner Production, 143, 757-768. https://doi.org/10.1016/j. jclepro.2016.12.048.

Gordon, R. (2017). The rise and fall of American growth: The U.S. standard of living since the civil war. Princeton: Princeton University Press.

Griggs, et al. (2013). Sustainable development goals for people and planet. Nature, 495, 305-307.

Hendrickson, J. R., et al. (2008). Principles of integrated agricultural systems: Introduction to processes and definition. Renewable Agriculture and Food Systems, 23(4), 265-271.

Klein, J. T., Grossenbacher-Mansuy, W., Häberli, R., Bill, A., Scholz, R. W., \& Welti, M. (2012). Transdisciplinarity: Joint problem solving among science, technology, and society: An effective way for managing complexity. Basel: Birkhäuser.

Krall, L. (2018). The economic legacy of the Holocene. The Ecological Citizen, 2(1), 67-76.

Latour, B. (2017). Facing Gaia: Eight lectures on the new climatic regime. Cambridge: Polity Press.

LERU (The League of European Research Universities). (2018). Double investment in research, innovation and education to boost Europe's competitiveness and sustainability. Statement March 2018. https://www.leru.org/files/Publications/Double-investment-in-research-innovation-and-education. pdf. Accessed: May 14, 2018.

Lovelock, J. (2005). Gaia: Medicine for an ailing planet. London: Gaia Books. ISBN 1-85675-231-3.

Magdoff, F. (2007). Ecological agriculture: Principles, practices, and constraints. Renewable Agriculture and Food Systems, 22(2), 109-117.

Marshal, A., \& Lozeva, S. (2009). Questioning the theory and practice of biomimicry. International Journal of Design \& Nature and Ecodynamics, 4(1), 1-10.

McNeill, J. R. (2000). Something new under the sun. New York: Norton.

McNeish, J. A. (2018). Resource extraction and conflict in Latin America. Columbia Internacional, 93, 3-16. https://doi.org/10.7440/colombiaint93.2018.01.

Morgan, M. S., \& Grüne-Yanoff, T. (2013). Modeling practices in the social and human sciences. An Interdisciplinary Exchange. Perspectives on Science, 21(2), 143-156.

Mulrow, J. S., Derrible, S., Ashton, W. S., \& Chopra, S. S. (2017). Industrial symbiosis at the facility scale. Journal of Industrial Ecology, 21, 559-571.

OECD (Organization for Economic Cooperation and Development). (2014). Income inequality update: Rising inequality: Youth and poor fall further behind. https://www.oecd.org/social/OECD2014Income-Inequality-Update.pdf. Accessed 7 July 2018.

Pocheco. (2018). http://www.pocheco.com/lentreprise/?lang=en. Accessed February 1, 2018.

Pretty, J. (2009). Can ecological agriculture feed nine billion people? Monthly Review, 61, 46-58.

Rees, W. E. (2003). Economic development and environmental protection: An ecological economics perspective. Environmental Monitoring and Assessment, 86, 29-45.

Sachsenmaier, D. (2013). Countries globalized but education lagging. Yale Center for the Study of Globalization. https://yaleglobal.yale.edu/content/countries-globalized-education-lagging. Accessed 6 Oct 2018.

Schand, H., et al. (2018). Global material flows and resource productivity: Forty years of evidence. Journal of Industrial Ecology, 22(4), 827-838. https://doi.org/10.1111/jiec.12626.

Scheffer, M. (2009). Critical transitions in nature and society. Princeton, NJ: Princeton University.

Schulze, M., Heidenreich, S., \& Spieth, P. (2018). The impact of energy management control systems on energy efficiency in the German manufacturing industry. Journal of Industrial Ecology, 22(4), 813-826. https://doi.org/10.1111/jiec.12625.

Shi, T., \& Gill, R. (2005). Developing effective policies for the sustainable development of ecological agriculture in China: The case study of Jinshan County with a systems dynamics model. Ecological Economics, 53(2), 223-246.

Shuman, M. (2006). The small-mart revolution: How local businesses are beating the global competition. Okland: Berrett-Koehler Publishers.

Stiegler, B. (2015). Automatic Society 1: The future of work, translated in La deleuziana-Online Journal of Philosophy-ISSN 2421-3098. No.1/2015-crisis of the European biopolitics, pp. 121-140.

Stojanovic, M. (2017). Biomimicry in Agriculture: Is the ecological system-design model the future agricultural paradigm? Journal of Agricultural and Environmental Ethics. https://doi.org/10.1007/s1080 6-017-9702-7. 
Vallor, S. (2016). Technology and the virtues: A philosophical guide to a future worth wanting. Oxford: Oxford University Press.

Vallor, S. (2017). Presidential address at the Society for Philosophy and Technology conference 'SPT 2017', Darmstadt, Germany.

van Veenhuizen, R. (Ed.). (2006). Cities farming for the future: Urban agriculture for green and productive cities. Philippines: International Institute of Rural Reconstruction and ETC Urban Agriculture.

Weinberg, J., Nichols, S., \& Stich, S. (2008). Normativity and epistemic intuitions. In J. Knobe \& S. Nichols (Eds.), Experimental philosophy (pp. 17-46). Cambridge: Cambridge University Press.

Weinstein, J. R. (2007). Adam Smith's moral philosophy the wealth of nations and the morality of OpulenceEvensky's. In W. J. Samuels, J. E. Biddle, \& R. B. Emmett (Eds.), A research annual (research in the history of economic thought and methodology, Volume 25 Part 1) (pp. 61-69). Bingley: Emerald Group Publishing Limited.

Werner, S. (2017). District heating and cooling in Sweden. Energy, 126, 419-429.

Whitbeck, C. (2011). Ethics in engineering practice and research. Cambridge: Cambridge University Press.

Zwier, J., \& Blok, V. (2017). Saving Earth. Techné: Research in Philosophy and Technology, 21(2/3), 222-242.

Zwier, J., Blok, V., \& Lemmens, P. (2015). The ideal of a zero-waste humanity: Philosophical reflections on the demand for a bio-based economy. Journal of Agricultural and Environmental Ethics. https:// doi.org/10.1007/s10806-015-9538-y.

Publisher's Note Springer Nature remains neutral with regard to jurisdictional claims in published maps and institutional affiliations. 